\title{
From a waste to a valuable resource: Combined application of water treatment residual and compost improves maize productivity
}

T. GWANDU ${ }^{1 *}$, H. NEZOMBA ${ }^{2}$, F. MTAMBANENGWE ${ }^{2}$, S. CHIVASA ${ }^{3}$, K. DOBSON ${ }^{4}$, M.LARK $^{5}$ AND K. JOHNSON ${ }^{1}$

${ }^{1}$ Department of Engieering, Durham University, UK

(karen.johnson@durham.ac.uk)

${ }^{2}$ Department of Soil Science \& Agricultural Engineering,

University of Zimbabwe, Zimbabwe

(fmtamba@gmail.com; hatienez@yahoo.co.uk)

${ }^{3}$ Department of Biological Sciences, Durham University, UK

(stephen.chivasa@durham.ac.uk)

${ }^{4}$ Department of Civil \& Environmental Engineering,

University of Strathclyde, Scotland, UK

(kathrine.dobson@strath.ac.uk)

${ }^{5}$ School of Biosciences, University of Nottingham, UK

(murray.lark@nottingham.ac.uk)

(*Correspondence: tariro.gwandu@durham.ac.uk)

Water treatment residual (WTR) is a by-product of municipal clean water treatment which is normally disposed to landfill. WTR production is anticipated to increase as the demand for potable water rises, especially in sub-Saharan Africa (SSA) due to rapid population growth and urbanisation; this has driven municipalities to look for alternative ways to utilise this product and to address SDG12 by reusing wastes in the circular economy. Although significant strides have been made into research on use of WTR as a soil amendment, there are mixed reports on its efficacy at improving either soil structure or plant yield. We do know that nutrients and specifically phosphorus (P) adsorption by both the aluminium $(\mathrm{Al})$ and/or iron $(\mathrm{Fe})$ oxides in WTR, have a deleterious effect on plant growth. We present results on the co-application of WTR with an organic plant based compost together with inorganic $\mathrm{P}$ additions in a 5 week greenhouse maize pot trial. There were no significant differences in maize growth and biomass production between the coamendment and sole compost amendments at $\mathrm{P}<0.05$. Addition of $\mathrm{P}$ further increased maize dry matter yield two fold in the co-amendment, a $403 \%$ increase compared to the unamended control. Preliminary findings show that WTR can be co-applied with another organic nutrient resource without incurring a yield penalty and thus could be a sustainable option for reusing WTR to enhance environmental protection. 